\title{
RESULTS ON A PEDAGOGIC APPROACH FOR TAILORING PUBLIC HEALTH INTERVENTIONS TO MINIMISE OPPORTUNISTIC INFECTIONS
}

\author{
A. Peña-Fernández ${ }^{1}$, C. Lobo-Bedmar², M.A. Peña ${ }^{3}$ \\ ${ }^{1}$ De Montfort University, School of Allied Health Sciences (UNITED KINGDOM) \\ ${ }^{2}$ IMIDRA, Departamento de Investigación Agroambiental (SPAIN) \\ ${ }^{3}$ Universidad de Alcalá, Departamento de Ciencias Biomédicas (SPAIN)
}

\begin{abstract}
We are performing curriculum modifications on the first year BSc (Hons) Biomedical Science module "Basic Microbiology" (De Montfort University, UK) to increase students' knowledge of basic medical parasitology and infectious diseases, so these students can acquire the necessary skills to tackle their final degree module "Medical Microbiology". Following student feedback on a novel short intervention in $2017 / 18$ to promote awareness about human immunodeficiency virus (HIV), we have created an engaging workshop session to cover not only HIV but also the opportunistic infections that can affect HIV patients that have developed acquired immune deficiency syndrome (AIDS) and how to prevent them. The objective of this work was to evaluate the effectiveness of the improved workshop developed and to collect students' impressions to perform further modifications if needed. Briefly, students were required to develop public health measures for HIV positive patients with two different degrees of immunosuppression (i.e. with CD4+ T cells in peripheral blood above and below 200 cells/ $\mu \mathrm{l}$ ) to prevent exposure and infection from opportunistic pathogens such as Cryptosporidium spp., Toxoplasma gondii or Pneumocystis jirovecii from: a) sexual exposures; b) intravenous drug use; b) environment and work; c) food and water; d) foreign travel. Students, following evidence-based public health methodology, tailored their measures or interventions using the most up-to-date information reported in the literature regarding HIV chemoprophylaxis and recent guidelines published by US Department of Health and Human Services on HIVIAIDS treatment and prevention. Interventions were critically analysed with all students in the last $20 \mathrm{~min}$. of the workshop, which was repeated several times due to the number of students $(n=203)$. The objectives of this workshop were evaluated by careful analysis of a specific feedback questionnaire ( $\mathrm{n}=46$ out of 203) voluntarily completed by students at the end of the workshop. The questionnaire showed the following feedback: $80.4 \%(65.2 \%$ agreed; $15.2 \%$ strongly agreed $)$ indicated that they learnt how to identify public health interventions; and $95.7 \%$ (56.5\% agreed; $39.1 \%$ strongly agreed) indicated that they would be able to establish measures to reduce HIV transmission and prevent opportunistic infections. Additionally, 95.7\% (39.1\% agreed; 56.5\% strongly agreed) indicated that the workshop helped them to understand the relevance of local and global interventions. Finally, $97.8 \%$ of responders considered that the content $(52.2 \%$ agreed; $45.7 \%$ strongly agreed) and duration $(60.9 \%$ agreed; $37 \%$ strongly agreed) of the workshop was appropriate; and $89.1 \%(58.7 \%$ agreed; $30.4 \%$ strongly agreed) and $73.9 \%$ (41.3\% agreed; $32.6 \%$ strongly agreed) enjoyed and were satisfied with the workshop provided, respectively. In conclusion, the improved workshop developed would seem to be effective for promoting sexual and public health education to minimise opportunistic pathogen infections in relevant patients when delivered to students with a basic knowledge of microbiology and parasitology.
\end{abstract}

Keywords: HIVIAIDS, preventive education, opportunistic infections training, medical parasitology.

\section{INTRODUCTION}

The HIVIAIDS pandemic remains an important threat to public health as current treatments are not successful in destroying proviral HIV DNA in cells [1]. Thus, Public Health England's report on HIV suggests different approaches such as enhancing HIV test coverage among heterosexual and men that have sex with men to reduce undiagnosed infection in people at increased risk of exposure and maintaining high treatment and care standards [2].

Appropriate condom use, pre-exposure prophyaxis (PrEP) and post-exposure prophyaxis (PEP), are important tools to reduce HIV transmission. However, the awareness for these chemoprophylaxis preventive methods, specifically for PrEP, is low [3]. Very poor general awareness in chemoprophylaxis preventive methods have been recorded in students enrolled in two human health science programmes 
at De Montfort University (DMU, Leicester, UK) after introducing a short pedagogic intervention to increase HIV awareness in their programmes, specifically, second year BMedSci Medical Science in 2016/17 [4] and first year BSc Biomedical Science (BMS) students in 2017/18 [5].

Following feedback, we have improved our pedagogic intervention to increase engagement and to cover HIV prevention and prevention of opportunistic infections in HIV patients that have developed AIDS. The objective of this work was to evaluate the effectiveness of the improved workshop developed and to collect students' impressions to perform further modifications if needed.

\section{METHODOLOGY}

A description of the initial pedagogic intervention implemented in BMedSci, structure and methods used, is described in Peña-Fernández et al. (2017) [4]. To introduce the HIV awareness pedagogic intervention in our BMS programme, we performed a series of curriculum modifications in the level 4 module "Basic Microbiology for Biomedical Science", modifications that have been described in previous communications [5]. Following module level feedback provided by students enrolled in the "Basic Microbiology' module, we have performed different changes and updated our overall training as follows, briefly: i) introduction of two hour lectures, to cover viruses and HIV; ii) introduction of a 1 hour workshop, in which students were asked to develop public interventions and recommendations using Evidence Based Public Health methodology [6] in conjunction with up-to-date evidence published in the literature and recent reports from relevant public health organisations:

- A) Prevent future HIV infections and promote consistent and correct use of barriers, including male and female condoms and dental dams. Students were provided with up-to-date articles on PEP and PrEP and the fact sheets for appropriate use of male/female condom and dental dam published by Centers for Disease Control (CDC) [7].

- B) Develop public health measures for HIV positive patients with CD4+ T cells in peripheral blood above and below 200 cells $/ \mu$ lo prevent exposure and infection from opportunistic pathogens from: a) sexual exposures; b) intravenous drug use; b) environment and work; c) food and water; d) foreign travel. Students were provided with the Guidelines for the Prevention and Treatment of Opportunistic Infections in HIV-Infected Adults and Adolescents produced by the US Department of Health and Human Services [8].

The workshop was repeated several times during the first term of the current academic course (2018/19) due to the number of $1^{\text {st }}$ year BMS students $(n=203)$. Students designed their interventions in small groups and then discussed them with the rest of the class and the academic lead who collectively and constructively critiqued the work. A feedback questionnaire was distributed immediately after completion of the workshop. Ethical approval was provided by the Research Ethics Committee at DMU (Ref. 1729).

\section{RESULTS}

Only forty-six students voluntarily completed the specific feedback-questionnaire at the end of the workshop. In general, the workshop and exercises proposed were well-received by BMS students. Thus, $97.8 \%$ of responders considered that the content $(52.2 \%$ agreed; $45.7 \%$ strongly agreed; Fig $1 . A)$ and duration $(60.9 \%$ agreed; $37 \%$ strongly agreed; Fig 1.B) of the workshop was appropriate. Participants also reported high levels of enjoyment and satisfaction, respectively $89.1 \%$ (58.7\% agreed; $30.4 \%$ strongly agreed; Fig 1.C) and 73.9\% (41.3\% agreed; 32.6\% strongly agreed; Fig 1.D).

A

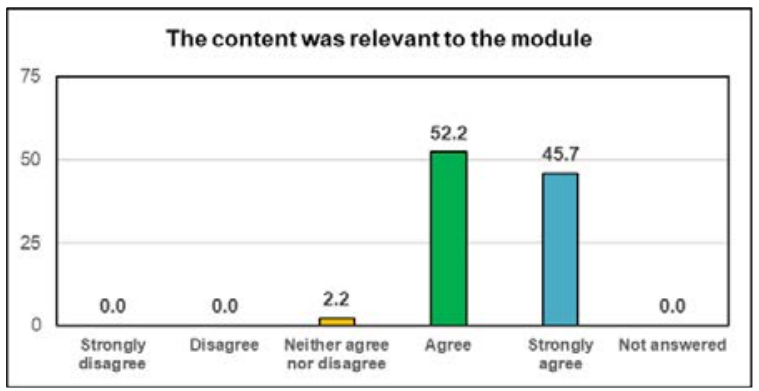

B

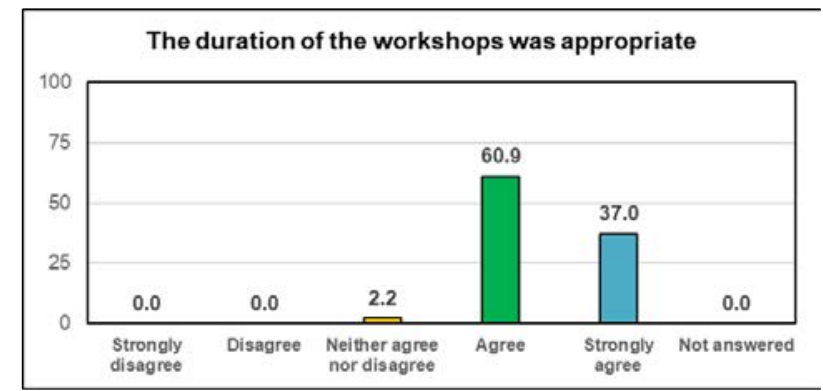


C

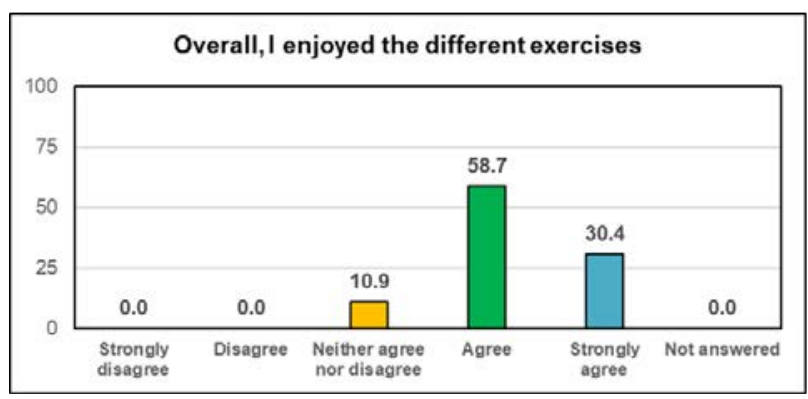

D

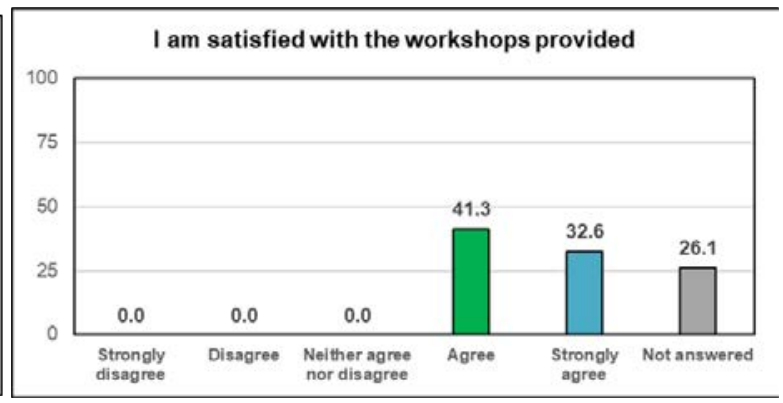

Figure 1: Students' opinion (\%) regarding content, duration, enjoyment and satisfaction of the HIVIAIDS workshop

In relation to acquisition of knowledge or skills, $80.4 \%$ (65.2\% agreed; $15.2 \%$ strongly agreed) indicated that they learnt how to identify public health interventions (Fig. 2). A small proportion of students $(19.5 \%$ : $4.3 \%$ disagree; $15.2 \%$ neither agree nor disagree) reported doubts regarding the process followed for selecting or identifying public health interventions, which could be attributed to the fact that this exercise was the first time that they were managing different scientific articles/reviewing the literature. Despite this percentage, $95.7 \%$ (56.5\% agreed; $39.1 \%$ strongly agreed) of students indicated that they would be able to establish measures to reduce HIV transmission and prevent opportunistic infections (Fig. 2), although most students showed some limitation in the tailoring of recommendations for preventing opportunistic infections. The general limitation observed in students in each delivered workshop regarding how to prevent opportunistic infections in HIV positive patients in different scenarios could be attributed to different factors, such as: lack of information in human and opportunistic pathogens, as these topics are initially covered in the second term in BIOM1009 "Basic Microbiology for Biomedical Science" and in further detail in the level 6 BMS module "Medical Microbiology"; the short time available to complete the workshop; and some difficulty in understanding the terminology.

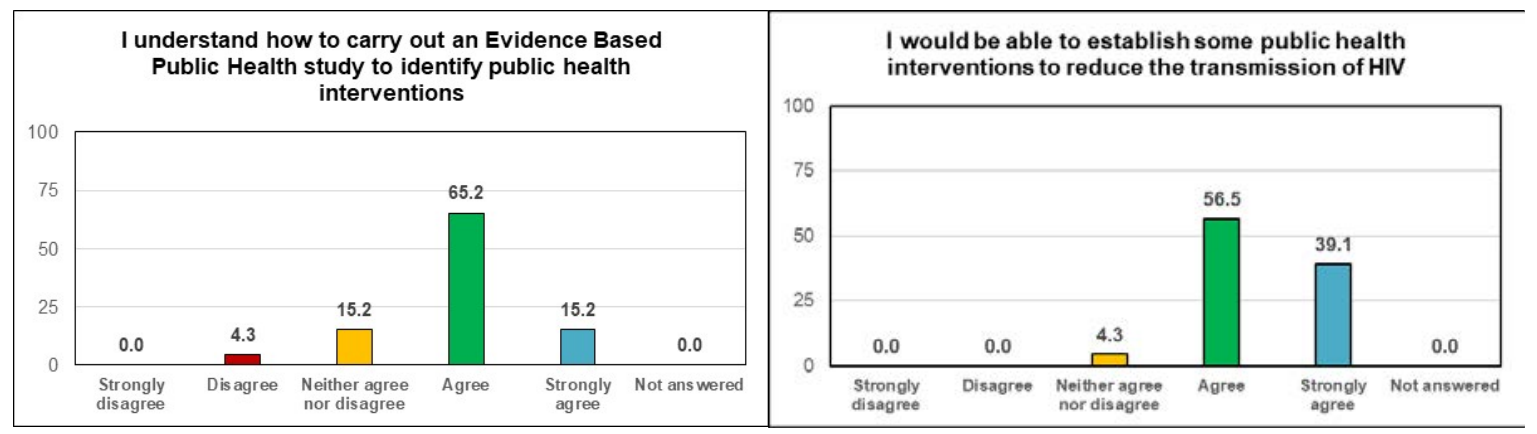

Figure 2: Students' opinion (\%) regarding acquisition of knowledge/skills after completing the workshop.

Finally, $95.7 \%$ (39.1\% agreed; $56.5 \%$ strongly agreed) indicated that the workshop helped them to understand the necessity of tackling the HIVIAIDS pandemic at local and global levels; and $63 \%(54.3 \%$ agreed; $8.7 \%$ strongly agreed) learnt about HIV chemoprophylaxis (Fig 3). A proportion of students (28.3\%; Fig 3) did not answer the question regarding chemoprophylactic preventive methods (PEP and PrEP), which may indicate that students did not acquire proper knowledge of these critical tools to prevent HIV infection, an issue that we will need to study further. A specific question regarding HIV chemoprophylaxis will be provided in the final module level feedback (usually released in April/May before the end of the course) to help with the analysis of this concerning result. However, our results would initially suggest that further modifications in the training would be needed to facilitate the awareness of preventive tools available to tackle the HIVIAIDS pandemic and to provide undergraduate students with the necessary skills and tools to protect their health. 


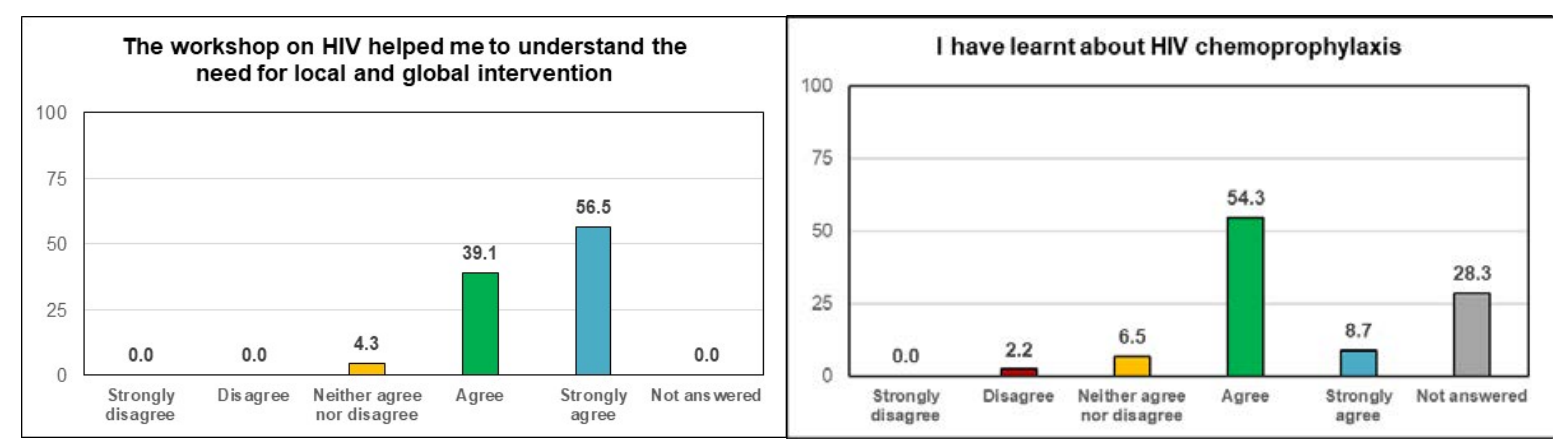

Figure 3: Students' opinion (\%) regarding acquisition of knowledge/skills after completing the workshop

\section{CONCLUSIONS}

In conclusion, the improved workshop developed would seem to be effective for promoting sexual and public health education to minimise HIV infections and suggest recommendations to potential future HIV patients from opportunistic pathogen infections when delivered to students with a basic knowledge of microbiology and parasitology. However, our results would also suggest performing further studies and small modifications in the workshop developed to increase awareness on HIV preventive tools available and opportunistic infections in immunosupressed patients.

\section{REFERENCES}

[1] Debyser Z., Vansant G., Bruggemans A., Janssens J., Christ F. Insight in HIV Integration Site Selection Provides a Block-and-Lock Strategy for a Functional Cure of HIV Infection. Viruses 2018; 11(1). pii: E12. doi: 10.3390/v11010012.

[2] Nash S, Desai S, Croxford S, Guerra L, Lowndes C, Connor N, Gill ON. Progress towards ending the HIV epidemic in the United Kingdom: 2018 report. November 2018, Public Health England, London.

[3] Dolezal C., Frasca T., Giguere R., Ibitoye M., Cranston RD., Febo I., Mayer KH., McGowan I., Carballo-Diéguez A. Awareness of Post-Exposure Prophylaxis (PEP) and Pre-Exposure Prophylaxis (PrEP) Is Low but Interest Is High Among Men Engaging in Condomless Anal Sex With Men in Boston, Pittsburgh, and San Juan. AIDS Educ Prev 2015; 27(4):289-97.

[4] Peña-Fernández A., Peña MA., Evans MD. Introducing training related to the use of drugs to protect humans from HIV infection. ICERI2017 Proceedings 2017; 7123-7127. ISBN: 978-84-697-6957-7.

[5] Peña-Fernández A., Peña MA., Escalera JB. Teaching intervention to enhance HIV infection awareness in a biomedical science degree. ICERI2018 Proceedings; 5223-5227. ISBN: 978-84-0905948-5.

[6] Brownson R.C., Gurney J.G., Land G.H. Evidence-based decision making in public health. Journal of Public Health Management and Practice 1999; 5:86-97.

[7] CDC, 2019. Condom effectiveness website. Available at: https://www.cdc.gov/condomeffectiveness/index.html [Accessed 21/01/2019]

[8] Panel on Opportunistic Infections in HIV-Infected Adults and Adolescents. Guidelines for the prevention and treatment of opportunistic infections in HIV-infected adults and adolescents: recommendations from the Centers for Disease Control and Prevention, the National Institutes of Health, and the HIV Medicine Association of the Infectious Diseases Society of America. Available at http://aidsinfo.nih.gov/contentfiles/lvguidelines/adult_oi.pdf. [Accessed 21/01/2019]. 